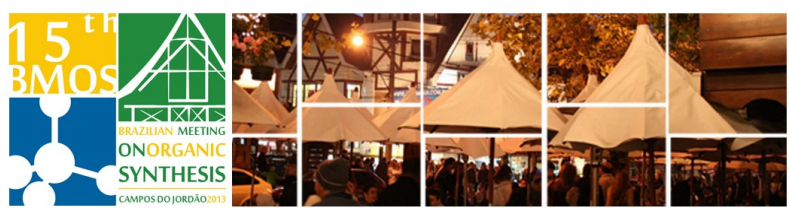

\title{
Synthesis of triterpenes and steroids derivatives as potential anti- HIV and cancer compounds.
}

\author{
Maria Candeia Kuliakita ${ }^{1,2^{\star}}(P G)$, Maurício Moraes Victor ${ }^{1,2^{\star}}(P Q)$, Jorge Mauricio David ${ }^{1,2 *}(P Q)$, \\ *e-mail: mariakuliakita2009@yahoo.com.br.
}

${ }^{1}$ Organic Chemistry Department, Chemistry Institute, and ${ }^{2}$ National Institute of Science and Technology/INCT-for Energy and Environment, UFBA, Salvador - BA, 40170-115, Brazil

Keywords: triterpenes, steroids, biological activity

\section{INTRODUCTION}

The Bevirimat ${ }^{\circledR} \mathbf{1}$ is a betulinic acid derivative (Figure 1) used in treatment of HIV, and melanoma ${ }^{1}$, isthe first drugin the class of anti retrovirals that hampers the maturation of AIDS $^{2}$. This being derived from a pentacyclic triterpene type lupine other triterpene derivatives have been synthesized with the similarity of this intuition to increase lipophilicity and improve the biological activity of these compounds.

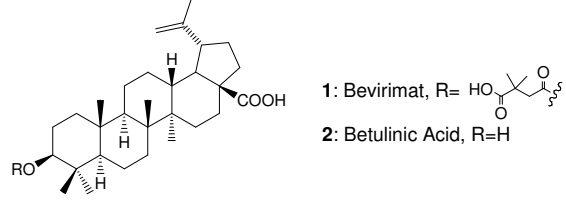

Figure 1: structures of anti-cancer agents

\section{RESULTS AND DISCUSSION}

Chemical modifications in $\mathrm{C}_{3}, \mathrm{C}_{28}$ and $\mathrm{C}_{30}$ of the triterpenes or steroids leads to modified compounds with pharmacological action marked by simple reactions. In this context, ten synthesized derivatives of triterpenes and steroids were synthesized as show in Figure 2 and are described in Table 1.

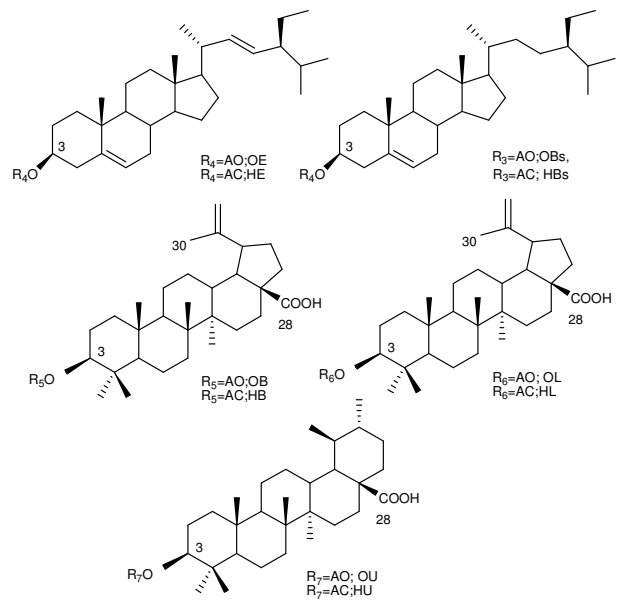

Figure 2: compounds synthesized

$$
\begin{gathered}
\mathrm{R}_{1} \mathrm{COOH}+\mathrm{R}_{2} \mathrm{OH} \frac{\mathrm{DMAP}, \mathrm{DIC}}{\mathrm{CH}_{2} \mathrm{Cl}_{2} \text {, t.a }} \mathrm{R}_{1} \mathrm{COOR}_{2} \\
\mathbf{R}_{\mathbf{1}}=\text { Triterpene or steroid } \\
\mathbf{R}_{\mathbf{2}}=\text { Oleic acid (AO) or caproic acid }(\mathrm{AC})
\end{gathered}
$$

Scheme 1: synthesis of derivatives

Biological activity tests are being made and some of them already presented activity against cancer. The derivatives were prepared using Steglich esterification as shown in Scheme 1. Some of these compounds were new.

Table1: Derivatives of triterpenes and steroids

\begin{tabular}{|l|l|l|l|}
\hline $\mathbf{R}_{1}$ and $\mathbf{A O}$ & $\%$ yield & $\mathbf{R}_{1}$ and $\mathbf{A C}$ & $\%$ yield \\
\hline $\mathrm{OE}$ & $72 \%$ & $\mathrm{HE}$ & $90 \%$ \\
\hline $\mathrm{OBs}$ & $87 \%$ & $\mathrm{HBs}$ & $86 \%$ \\
\hline $\mathrm{OB}^{\mathrm{a})}$ & $80 \%$ & $\mathrm{HBs}^{\text {a) }}$ & $94 \%$ \\
\hline $\mathrm{OU}^{\text {a) }}$ & $90 \%$ & $\mathrm{HU}^{\text {a) }}$ & $94 \%$ \\
\hline $\mathrm{OL}^{\text {a) }}$ & $61 \%$ & $\mathrm{HU}$ & $72 \%$ \\
\hline
\end{tabular}

a) Unpublished structures

\section{CONCLUSION}

Triterpenes and steroids are found in various plants. Their medicinal properties are extremely important, and synthesis of derivatives are a route to reduce the index of chronic diseases that affect humans. Preliminary tests were made and some of them ( $B$, $\mathrm{HB})$ have shown anti-cancer activity. These products were characterized by ${ }^{1} \mathrm{H}$ and ${ }^{13} \mathrm{C}$ NMR and IR.

\section{ACKNOWLEDGEMENTS}

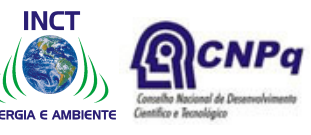

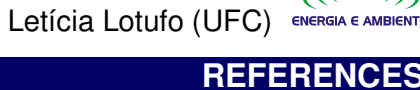

${ }^{1}$ Lee,K-H.;Bori, I. D.; Hung, H-Y.; Qian, K.; Chen, C-H.; Natschke,S. L. MTetrahedron Letters. 2012, 53, 19871989.

2.(a) Cunico, W.; Gomes, C. R. B.; Júnior, W. T. V.; Quím. Nova 2008, 31, 2111-2117; (b) Kashiwada, Y.; Hashimoto, F.; Cosentino, L. M.; Chen, C.-H.; Garrett, P. E.; Lee, K.H.; J. Med. Chem. 1996, 39, 1016-1017. 